\title{
Pathogenic potential and growth kinetics of Muko virus in mice and human-derived cells
}

\author{
Gianne Eduard L. Ulanday ${ }^{1}$, Satoshi Shimada ${ }^{1,2}$, Ngwe Tun Mya Myat $^{1}$, Takeshi Nabeshima $^{1}$, Kouichi Morita ${ }^{1,2}$ \\ and Daisuke Hayasaka ${ }^{1,2^{*}}$
}

\begin{abstract}
Background: Ticks have been long known as vectors of various pathogens, some of which can cause high fatality rates among infected individuals. Our enhanced tick surveillance around Nagasaki, Japan, led to the isolation and identification of a new strain of a recently identified Orbivirus, Muko virus (MUV). The orbiviruses have a wide host range, including humans, and is related to a spectrum of clinical outcomes. However, the zoonotic potential of some members of the genus, although reported, were not clearly elucidated. Hence, it is imperative to characterize newly isolated orbiviruses and investigate its ability to endanger public health.
\end{abstract}

Methods: In this study, we explored the in vivo pathogenicity of a newly isolated MUV strain (MUV-Hay) using a mouse model and demonstrated its growth kinetics in human-derived cells.

Results: Our results showed the ability of MUV-Hay to propagate in human neuronal and renal cells with some cytopathic effect. Furthermore, intracerebral inoculation of our new isolate caused high mortality in adult A129 mice.

Conclusion: Our study provided a first step to experimentally test the hypothesis, that MUV can replicate and produce cytopathic effect in human cells and demonstrate virulence in adult mice.

Keywords: Muko virus, Tick-borne virus, Mouse model, Human-derived cells

\section{Background}

Ixodid ticks transmit a number of viruses, including those of the families Bunyaviridae, Flaviviridae, Reoviridae, Rhabdoviridae, and Orthomyxoviridae [1-3]. Tick-borne viruses include highly pathogenic agents such as the tick-borne encephalitis virus (TBEV), Crimean-Congo hemorrhagic fever virus (CCHFV), and severe fever with thrombocytopenia syndrome virus (SFTSV).

Of those mentioned, cases of tick-borne encephalitis (TBE) and severe fever with thrombocytopenia syndrome (SFTS) have been reported in Japan $[4,5]$. A TBE case was confirmed in the southern area of Hokkaido, north island of Japan, and TBEV was isolated from

\footnotetext{
* Correspondence: hayasaka@nagasaki-u.ac.jp

${ }^{1}$ Department of Virology, Institute of Tropical Medicine (NEKKEN), 1-12-4 Sakamoto, Nagasaki 852-8523, Japan

${ }^{2}$ Leading Graduate School Program, Nagasaki University, 1-12-4 Sakamoto, Nagasaki 852-8523, Japan
}

\section{Biomed Central}

(c) 2016 The Author(s). Open Access This article is distributed under the terms of the Creative Commons Attribution 4.0 International License (http://creativecommons.org/licenses/by/4.0/), which permits unrestricted use, distribution, and reproduction in any medium, provided you give appropriate credit to the original author(s) and the source, provide a link to the Creative Commons license, and indicate if changes were made. The Creative Commons Public Domain Dedication waiver (http://creativecommons.org/publicdomain/zero/1.0/) applies to the data made available in this article, unless otherwise stated.

Ixodes ovatus in the endemic area [6]. On the other hand, more than 170 cases of SFTS have been identified in western Japan since 2005 (http://kanpoken.pref.yamaguchi.lg.jp/jyoho/page9/sfts_1.php). Although SFTSV has been detected in several species of ticks in China and Korea [7-13], we and another group were not able to isolate SFTSV from ticks collected by flagging during an epidemiological survey $[14,15]$.

To aid in the planning of public health measures such as early detection of cases and discrimination of viral from bacterial tick-borne infections, field studies are necessary in providing tick infection rates, species distribution, and level of endemicity. Our field collection of ticks aimed to identify viruses that are possible mammalian pathogens and obtain other data as part of tick surveillance in Japan.

Our efforts in the field sampling of ticks resulted to the identification of a new tick-borne virus, Tofla virus 
(TFLV), belonging to the genus Nairovirus, family Bunyaviridae, from Haemaphysalis flava and Haemaphysalis formsensis ticks [16]. Although the infectivity and pathogenicity of TFLV in humans and animals remain unclear, the virus exhibited ability to propagate in both monkey and human-derived cultured cells. TFLV also produced lethal infection in interferon- $\alpha / \beta$ receptor knockout (IFNAR KO) mice with marked gastrointestinal pathology [16].

Our enhanced tick surveillance in Nagasaki, located on the Japanese island of Kyushu, isolated an infectious agent that produced fatal infection in IFNAR KO mice. Next-generation sequencing (NGS) identified the pathogen as a new strain of Muko virus (MUV) which was first reported by Ejiri et al. [17].

The recently identified virus, MUV, belongs to the genus Orbivirus of the family Reoviridae, initially isolated from Ixodes turdus collected in Hyogo within the Kansai region on the Honshu island of Japan. In the same study, they showed that their isolate (MUV-S1) could replicate and induce cytopathic effect in animal-derived cell lines such as BHK-21 (Syrian hamster kidney), Vero E6 (African green monkey kidney), and CCL-141 (duck embryo) and exhibit lethal infection in suckling mice after intracerebral inoculation. In addition, the genetic association of MUV to Kemerovo and Tribec viruses suggests that MUV may negatively impact human health and be a potential zoonotic agent. Collectively, their results raise the possibility that MUV may also cause disease among other animals including humans [17].

Since the prevention and control of pathogenic orbiviruses depend on current information, critical gaps in knowledge need to be addressed. The identification of host range susceptible to specific Orbivirus species and the molecular determinants involved in host specificity needs to be understood [18]. However, the pathogenicity in adult animals and infectivity in human cells were not elucidated in the previous study. Our study, therefore, has focused on in vitro infectivity of MUV in cells of human origin and demonstrates its in vivo virulence among adult mice.

\section{Methods}

\section{MUV isolation from ticks}

Ticks were collected by flagging in Nagasaki in January 2015 (Fig. 1), following the techniques applied in previous studies [14-16]. The pooled I. turdus ticks comprising five nymphs were homogenized using Micro Smash ${ }^{\text {tm }}$ MS-100R (TOMY DIGITAL BIOLOGY CO., LTD, Tokyo, Japan) with one stainless bead $(4.8 \varnothing)$ and $0.5 \mathrm{ml}$ of $2 \%$ fetal bovine serum (FBS) in Eagle's minimum essential medium (EMEM; Nissui Pharmaceutical Co., Tokyo, Japan) per reaction tube at $4500 \mathrm{rpm}$ for $15 \mathrm{~s}$ at $4{ }^{\circ} \mathrm{C}$. A total of $100 \mu \mathrm{l}$ of the supernatant was

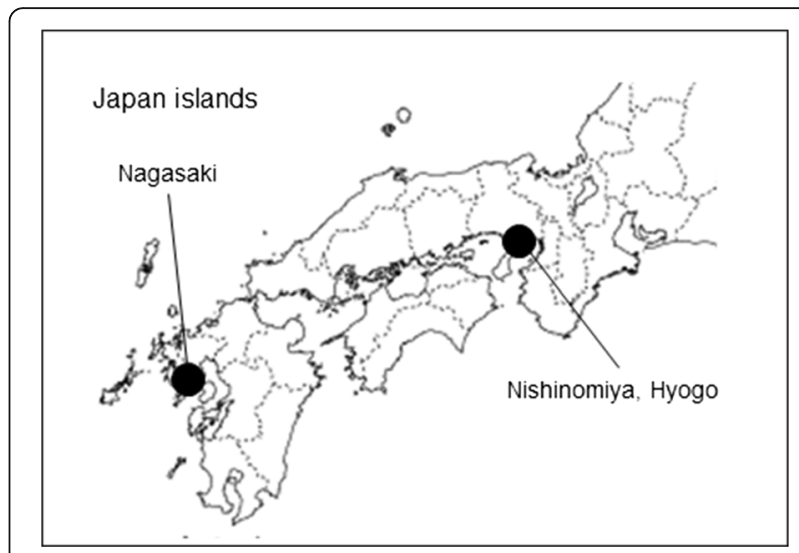

Fig. 1 Map showing the location of Nagasaki and Nishinomiya in Japan

intraperitoneally inoculated into adult A129 mouse. The post-mortem mouse spleen was collected after 6 days and homogenized in $2 \%$ FBS EMEM.

\section{MUV genome sequence}

RNA was extracted from the homogenized mouse spleen using RNeasy Lipid Tissue Mini Kit (Qiagen, Hilden, Germany). Next-generation sequencing (NGS) was performed using GS Junior 454 (Roche Diagnostic Cooperation, Branford, CT, USA). The full-length sequences were determined using the primers designed from the sequence previously reported [17].

\section{Phylogenetic analysis}

Phylogenetic analyses of the VP region of selected tickborne Orbivirus proteins and amino acid sequences were aligned using the DIALIGN-TX v1.0.2 and TrimAl v1.2 [19-21]. The substitution models were determined by ProtTest v3.4.1 while the phylogenetic trees were reconstructed by the maximum likelihood model using PhyML v3.0.1 [22, 23]. The following accession codes were obtained for phylogenetic analyses from GenBank: Baku virus (AHW57716.1), Colorado tick fever virus (NP_690891.1), Great Island virus (YP_003896058.1), Kemerovo virus (AGG68141.1), Lipovnik virus (ADM88603.1), Muko virus (BAT21343.1), Okhotskiy virus (AHL27158.1), Tribec virus (ADZ96219.1), and Wad Medani virus (YP_009158877.1).

\section{Virus and cells}

The homogenized spleen sample of mouse that was previously inoculated with tick homogenate was inoculated into BHK-21 cells. The infectious culture fluid was harvested 6 days post-inoculation, aliquoted, and kept as master virus stocks.

BHK-21, T98-G (human glioblastoma multiforme), SKN-SH (human neuroblastoma), and HEK-293 (human 
embryonic kidney) cells were maintained in EMEM containing $10 \%$ FBS.

\section{Mice}

The IFNAR KO (A129) mice were purchased from B \& $K$ Universal Limited and were mated in the facility at Nagasaki University. The B6 mice were purchased from CLEA Japan, Inc. B6 was chosen since it is known to be a standard mouse model in infection research.

\section{Infection of mice with MUV}

Adult ( $>8$ weeks old) A129 mice were assigned into one of the six dosage groups ( $n=6$ per group) prior to subcutaneous inoculation of $10^{-2}$ to $10^{3}$ plaque-forming units (pfu) of MUV in EMEM containing 2 \% FBS. On the other hand, adult B6 mice were inoculated with a single dose of MUV at $10^{3} \mathrm{pfu}(n=6)$. The mice were weighed daily and observed for clinical signs of disease for 14 days. Weight and mortality ratios were calculated to demonstrate MUV in vivo pathogenicity.

To assess any difference in viral replication within the different organs, A129 mice were subcutaneously infected with $10^{2}$ pfu of MUV, with three mice per group sacrificed at 1 and 3 days post-inoculation (pi). The thymus, lungs, spleen, liver, kidneys, small intestine, colon, cecum, brain, and spinal cord were removed following perfusion with cold phosphate-buffered saline (PBS). The small intestine, colon, and cecum were washed with cold PBS to remove fecal matter. Brain tissue was further classified and divided into two fractions, the brain cortex and non-cortex. The tissue segments were immediately submerged in RNAlater (Ambion, CA, USA) and stored at $-80{ }^{\circ} \mathrm{C}$ until they were used.

Viral replication in the different organs was assessed in A129 mice by quantitation of viral copy numbers using real-time RT-PCR. The total RNA was extracted from the previously prepared tissue segments using an RNeasy Lipid Tissue Mini Kit (Qiagen, Hilden, Germany). The MUV-specific primers and probes were designated based on viral segment 1 using Primer3web version 4.0.0 (http://primer3.ut.ee) [24, 25]. Primers used included forward primer MUV1_0745F20: 5'GGCCAGCTATTCATGGTTCG-3' and the reverse primer MUV1_0865R20: 5'-CGTCTCCAGCTCCGA TATGT-3', and the PrimeTime ${ }^{\circ}$ qPCR probe was MUV1_A_int: 5'-/56-FAM/TTATCTCGG/ZEN/AGGGA GGGGAT/3IABkFQ/-3' (Integrated DNA Technologies, IA, USA). The real-time RT-PCR reactions were performed using a One Step PrimeScript RT-PCR Kit (Takara Bio, Inc., Tokyo, Japan) detected by 7500 Real-time PCR System (Applied Biosystems, CA, USA). The copy numbers were calculated as ratio of the copy numbers of a standard control.

\section{Determination of MUV infectious titers}

Infectious titers of MUV-Hay were determined using a plaque-forming assay. Confluent BHK-21 cells were inoculated with serial dilutions of MUV culture fluid. The virus was allowed to adsorb for $1 \mathrm{~h}$ prior to the addition of an overlay medium (MEM with $1 \%$ methylcellulose (Sigma-Aldrich), 2 \% FBS). After an incubation of 4 days at $37{ }^{\circ} \mathrm{C}$ with $5 \% \mathrm{CO}_{2}$, the overlay was carefully removed and washed with PBS. Fixation of cells was done using $4 \%$ paraformaldehyde in PBS at room temperature for at least $30 \mathrm{~min}$. Crystal violet was used to visualize plaques after staining overnight at room temperature. The viral titers were expressed as plaque-forming unit per milliliter.

\section{Inoculation of MUV into human-derived cell lines}

A primary master stock of MUV was used to inoculate T98-G, SK-N-SH, and HEK-293 cells at multiplicity of infection (MOI) of 0.001 and incubated at $37{ }^{\circ} \mathrm{C}$ with $5 \% \mathrm{CO}_{2}$. After $1 \mathrm{~h}$ adsorption, supernatants were removed and fresh EMEM were added. The experiment was performed in triplicate. The culture fluids were harvested daily for 3 days pi and were kept at $-80{ }^{\circ} \mathrm{C}$ until analysis. Infectious titers of MUV were determined using a plaque-forming assay.

\section{Results \\ Isolation of MUV}

Inoculations with homogenized tick pools of I. turdus collected from Nagasaki during the study period resulted in fatal outcomes among A129 mice at 6 days pi. To identify the causative agent of infection, we determined the genome sequence using RNA samples extracted from dead mouse spleen. NGS identified a homologous sequence of MUV, and full sequences of the ten segments were determined by Sanger sequencing. The nucleotide and amino acid sequence identities between the two strains of MUV, MUV-S1 and MUV-Hay, were 96.6-98.7 \% and 96.8-99.4 \% in each segment, respectively (Table 1). The phylogenetic analyses revealed that the two strains of MUV clustered with Tribec virus and Lipovnik virus within the genus Oribivirus, family Reoviridae (Fig. 2).

\section{Pathogenicity of MUV in adult immunocompetent mice} A previous study has shown that intracerebral inoculation with $10^{3}$ pfu of MUV-S1 caused fatal infection in suckling mice of outbred ddY mice [17]. However, the pathogenic potential in adult mice is not known. Thus, we subcutaneously inoculated MUV-Hay into adult B6 mice. However, no mice exhibited apparent clinical signs and mortality was not observed (data not shown). 
Table 1 Amino acid and nucleotide sequence comparison between MUV-S1 and MUV-Hay strains

\begin{tabular}{llllll}
\hline & \multicolumn{2}{l}{ Amino acid } & & \multicolumn{2}{l}{ Nucleotide } \\
\cline { 2 - 3 } \cline { 5 - 6 } & Identity (\%) & Length (aa) & & Identity (\%) & Length (bp) \\
\hline Segment 1 & 99.1 & 1284 & 98.5 & 3892 \\
Segment 2 & 99.4 & 908 & & 98.1 & 2793 \\
Segment 3 & 99.0 & 628 & 97.3 & 1935 \\
Segment 4 & 97.9 & 529 & 97.6 & 1736 \\
Segment 5 & 98.2 & 553 & & 97.9 & 1729 \\
Segment 6 & 99.4 & 537 & 98.7 & 1668 \\
Segment 7 & 98.1 & 368 & 96.6 & 1196 \\
Segment 8 & 98.3 & 357 & & 97.9 & 1184 \\
Segment 9 & 96.8 & 312 & & 98.0 & 1034 \\
Segment 10 & 98.6 & 214 & 98.6 & 705 \\
\hline
\end{tabular}

\section{Pathogenicity of MUV in adult A129 mice}

We isolated MUV from dead A129 mice inoculated with a homogenized tick sample. Therefore, we next examined the pathogenicity of the MUV infection in adult A129 mice. Following subcutaneous inoculation with $10^{3}$ and $10^{2} \mathrm{pfu}$ of MUV-Hay, weight reductions were observed at 2 to 3 days pi and all mice died at 4 to 6 days pi (Fig. 3a, b). Some of the $10^{1}$ and $10^{\circ}$ pfu-inoculated mice recovered after weight reductions (Fig. 3a, c). Inoculation dose-dependent mortality was clearly observed (Fig. 3b, c), and the $\mathrm{LD}_{50}$ of MUV was $10^{\circ} \mathrm{pfu}$.
Viral RNA was detected in some tissues at 1 day pi (Fig. 4a) and increased in every tissue at 3 days pi (Fig. 4b), indicating that MUV rapidly replicated in these tissues. The viral RNA levels varied among the tissues with the levels found in the spleen higher than those of other tissues at 3 days pi (Fig. 4b).

\section{MUV infectivity and replication in human-derived cell lines}

We next examined whether MUV could infect and propagate in human cells. Human-derived SK-N-SH, T98-G, and HEK-293 cells were inoculated with MUV, and infectious virus titers from the different culture fluids were quantified by standard plaque assay. Figure 5 shows the ability of MUV to replicate and propagate in the three selected human cell lines with varied efficiency. The yield of infectious virus at time 0 differed between the neuronal cells (SK-N-SH and T98-G) and the embryonic kidney-derived HEK-293 cells; nevertheless, all three cell lines revealed a time-dependent increase in viral titer. All showed peak growth at day 2 as was reported in other studies [17]. It is notable, however, that the viral titers of neuronal-derived cells decreased after day 2 pi in contrast to those of HEK-293. Cytopathic effect (CPE) of MUV infection on HEK-293 cells was more evident compared to that of T98-G cells while infected SK-N-SH cells showed inconclusive CPE (data not shown). These results suggest that MUV can infect and propagate in human-derived cells.

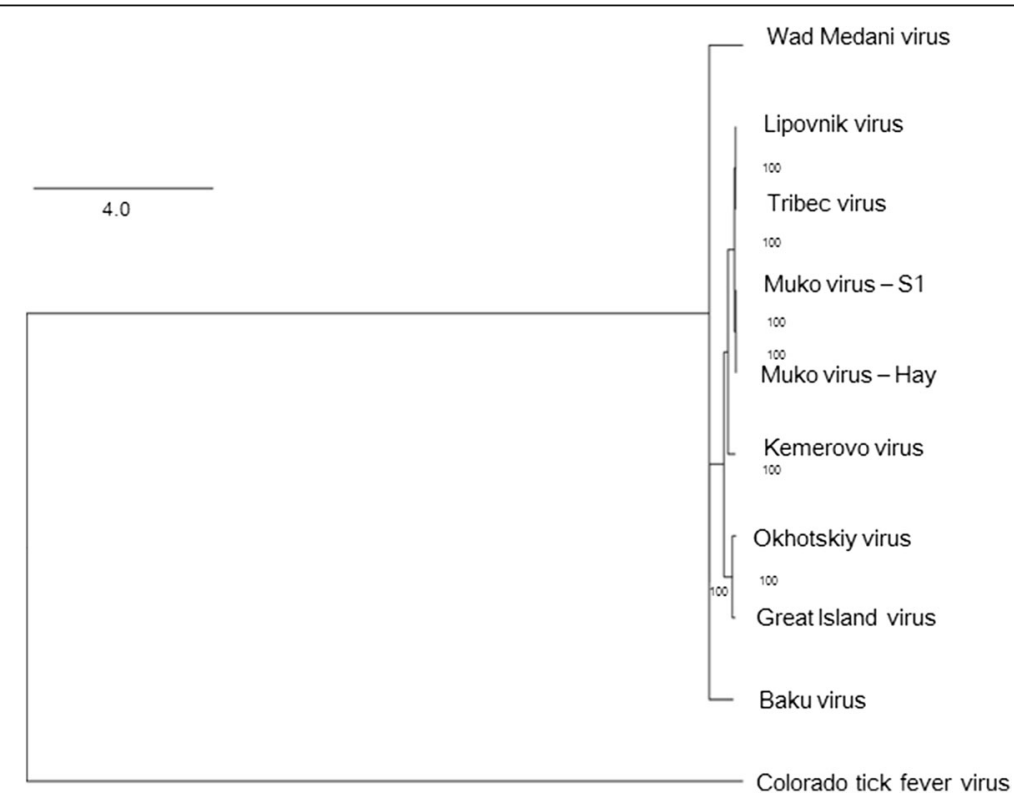

Fig. 2 Phylogenetic tree of tick-borne Orbiviruses. The phylogenetic tree was constructed based on the VP1 region by LG + G substitution model. Colorado tick fever virus, of the genus Cortivirus, was selected as an outgroup. One thousand bootstrap replications were conducted. Bootstrap values (shown as percentage) are described at the nodes 

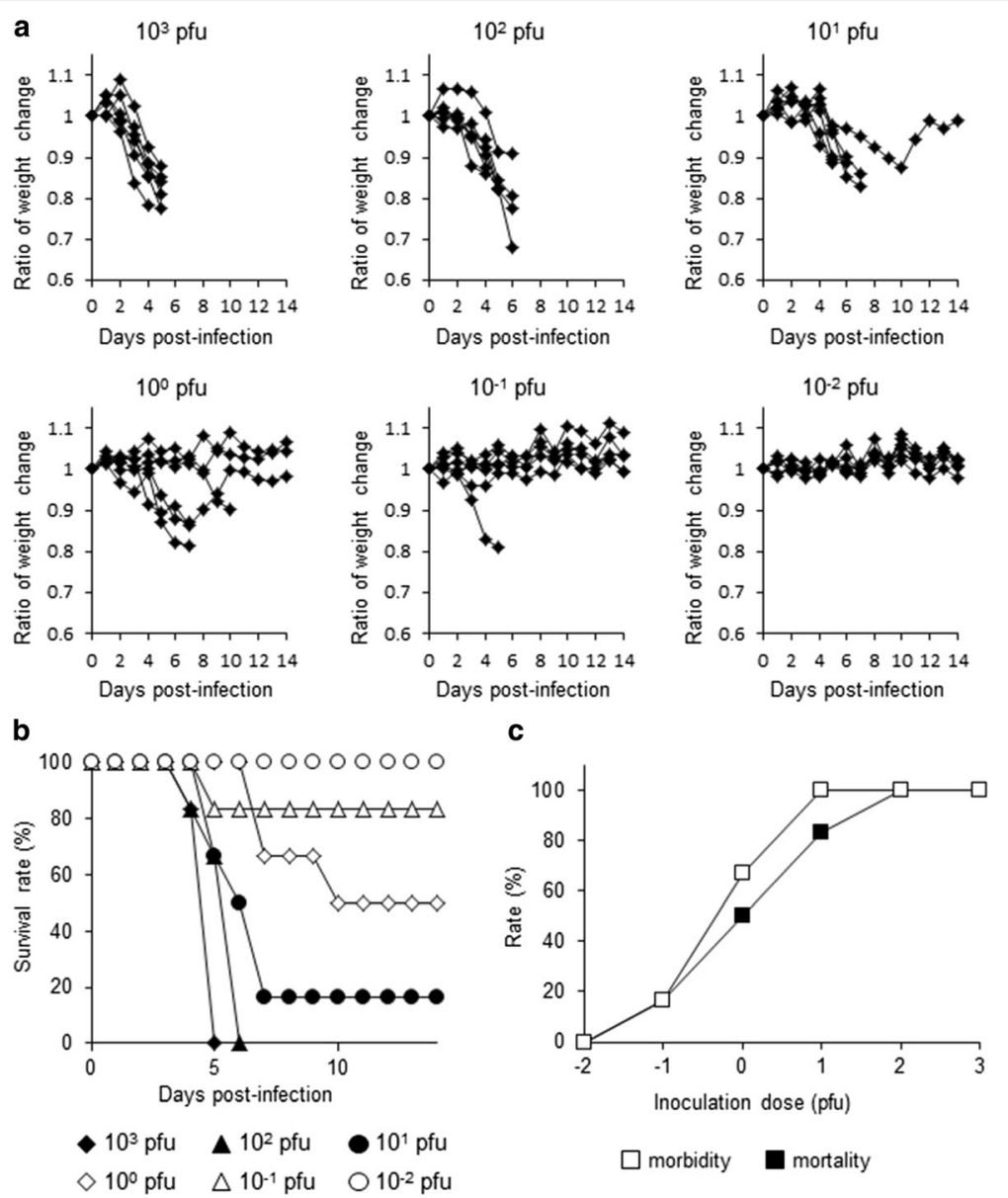

Fig. 3 Survival curves of A129 mice in six different dosage groups (total $n=36$ ) pertaining to inoculation dose ranging $10^{-2}$ to $10^{3}$ pfu of MUV ( $n=6$ per group). Each mouse within the groups was inoculated subcutaneously and observed for 14 days. a Weight changes expressed as weight ratios. b Survival rate per group. c Mortality and morbidity rates. Morbidity of mice was estimated by degree of weight loss
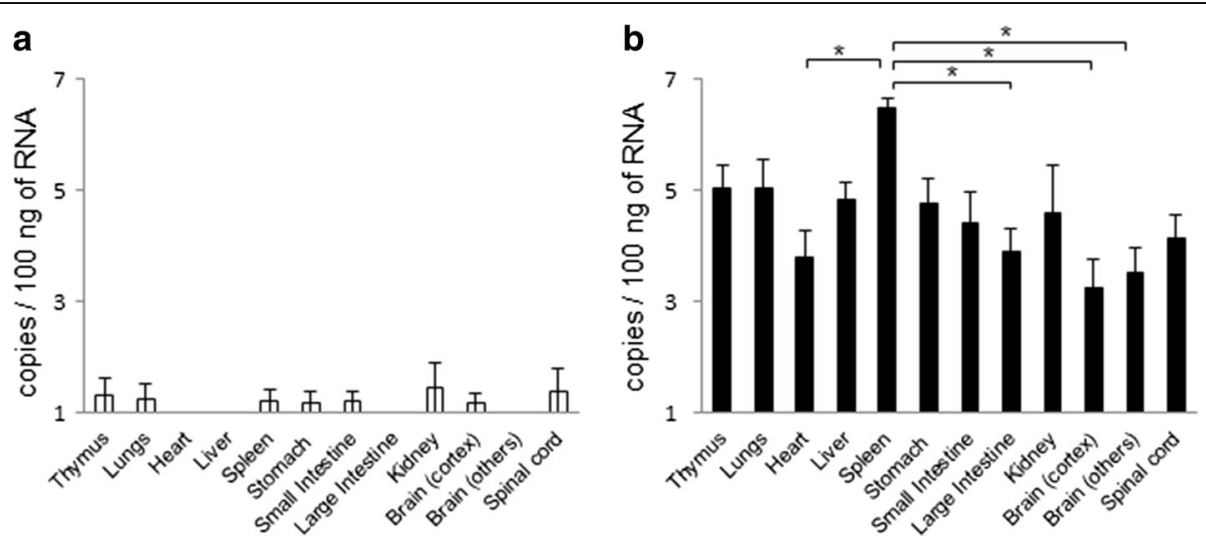

Fig. 4 Viral RNA levels in tissues of MUV-infected A129 mice at 1 (a) and 3 (b) days pi. Asterisks show the pairs that exhibit significant differences by Tukey's multiple comparison test that indicate $P<0.05$ by the analysis of variance 
HEK
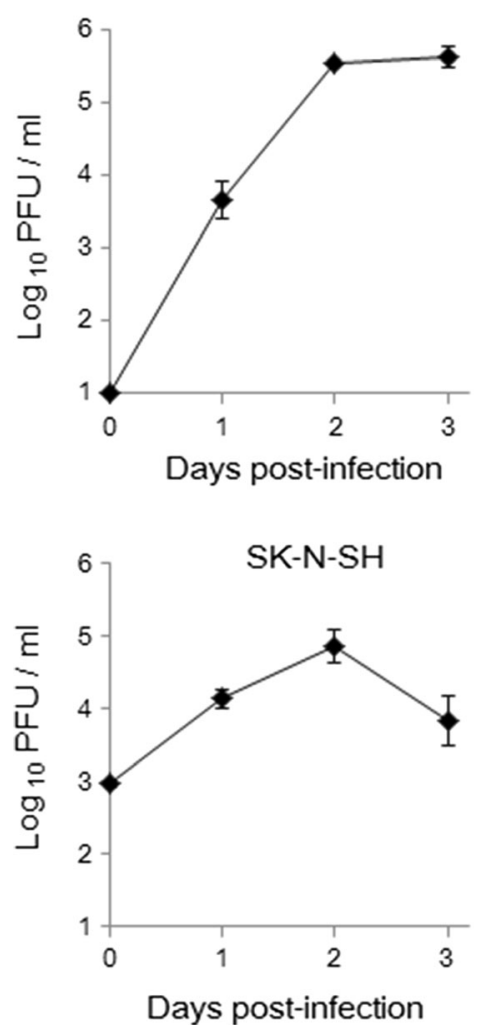

T98G

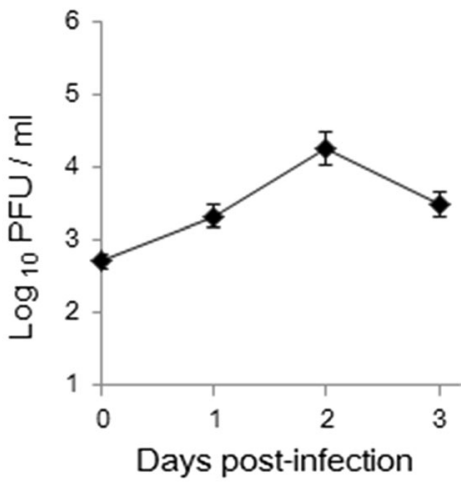

by plaque-forming unit per milliliter. Error bars represent the standard errors

\section{Discussion}

This study revealed the potential of MUV of infecting mammals including humans. MUV is a newly identified virus isolated from I. turdus in Japan; nonetheless, it is not clear whether MUV can cause any obvious pathology among humans and other animals. The main host of $I$. turdus is birds; thus, they may be the primary host of MUV. In support of that statement, the previous report on MUV showed infection and replication of the virus in avian cell culture. In addition, they also demonstrated MUV infectivity in rodent and primate cells [17]. The results of our study strengthen the hypothesis that MUV can infect and replicate on a wide range of hosts, including humans. The observed difference in infectious virus titers between the neuronal and the embryonic kidneyderived cells at time 0 provides an interesting avenue for further research. It is likely that cell-specific receptors and factors, specifically during the initial stages of viral replication, contributed to this phenomenon.

MUV exhibited lethal infection in A129 mice, although the mechanism of death in the MUV-infected A129 mice was unclear. On the other hand, MUV infection did not show any apparent clinical signs in adult B6 mice. This indicates that IFN-I responses are likely to be important for protection against MUV in mice. IFNAR $\mathrm{KO}$ mice such as A129 mice are useful animal models for in vivo infections with tick-borne Bunyaviruses such as CCHFV, Hazara virus, and TFLV, even though these viruses do not exhibit apparent pathogenicity in immunocompetent mice [16, 26-28]. Therefore, evaluation of antiviral effect of candidate compounds on in vivo viral replication in IFNAR KO mice can be a solution. Since these mice have minimal interferon-mediated immune response, any observed effect can be attributed to the compound administered. These suggest that A129 mice may be used as an alternative model for testing antiviral agents against tick-borne Bunyaviruses as well as Orbiviruses.

The Orbiviruses have a wide range of hosts, from ruminants to humans and exhibiting varied clinical outcomes. In fact, Bluetongue virus, the prototype Orbivirus, has caused devastating outbreaks in livestock leading to high economic losses while another member, Epizootic hemorrhagic disease virus, causes a hemorrhagic disease of deer $[18,29,30]$. The phylogenetic analysis revealed that MUV clustered with Lipovnik virus and Tribec virus and therefore suggests the possibility of MUV to be a zoonotic agent. 
MUV-S1 and MUV-Hay were isolated from ticks in Nishinomiya and Nagasaki, respectively [17]. The distance between Nishinomiya and Nagasaki is approximately $550 \mathrm{~km}$. I. turdus is distributed over a large area of Japan. Therefore, MUV may be distributed throughout Japan and may naturally circulate within ticks and animals including birds. Thus, further investigations such as seroepidemiological surveys of human and animal samples are an important priority to determine the level of infectivity among humans and other animals. In addition, further in vitro experiments using other cell lines originating from tissues of both human and nonhuman mammals will provide useful information in understanding the infectivity and tissue tropism of MUV.

Although our results do not strongly point out that MUV directly associated with pathogenicity to humans, we also cannot rule out the possibility of MUV to be an important human pathogen. Our work provided a first step to experimentally test the hypothesis that MUV can replicate and produce CPE in human cells, which was not included in the previous study [17].

\section{Conclusions}

We described in this study the growth characteristics of a newly isolated strain of MUV using human cell lines and also demonstrated its pathogenicity using a mouse model. Our isolation of a new MUV strain from ticks at a location far from the initial report warrants further investigation. Seroepidemiological surveys of human and animal samples throughout the region are of importance to determine the level of infectivity among humans and other animals. The possible role of interferon during the course of MUV infection should also be further elucidated. Thus, further in vitro experiments using other cell lines originating from tissues of both human and nonhuman mammals will provide useful information in understanding the infectivity and tissue tropism of MUV.

\section{Abbreviations}

MUV: Muko virus; TBE: Tick-borne encephalitis; TBEV: Tick-borne encephalitis virus; CCHFV: Crimean-Congo hemorrhagic fever virus; SFTS: Severe fever with thrombocytopenia syndrome; SFTSV: Severe fever with thrombocytopenia syndrome virus; TFLV: Tofla virus; IFNAR KO: Interferon- $\alpha / \beta$ receptor knockout; NGS: Next-generation sequencing; EMEM: Eagle's minimum essential medium; FBS: Fetal bovine serum; pi: Post-inoculation; pfu: Plaque-forming unit; CPE: Cytopathic effect

\section{Acknowledgements}

We thank Kazuhiro Takeda (Nagasaki University) for the tick collection and the members of the Department of Virology, Institute of Tropical Medicine, Nagasaki University, for their various support extended during this work.

\section{Funding}

This work was financially supported by a Health and Labor Sciences Research Grant on Emerging and Re-emerging Infectious Diseases from the Japanese Ministry of Health, Labor, and Welfare and Health and Labor Sciences Research Grants and also by KAKENHI (Grant-in-Aid for Scientific Research (B) (25304045) and Grant-in-Aid for Challenging Exploratory Research (15K15126)) from the
Japan Society for the Promotion of Science and the Joint Usage/Research Center on Tropical Disease, Institute of Tropical Medicine, Nagasaki University.

\section{Availability of data and materials}

Sequences of MUV-Hay were uploaded to GenBank ${ }^{\circledast}$ awaiting its assigned accession number

\section{Authors' contributions}

GELU performed the experiments of tick collection, sequencing of viral genome, titration of virus, and cell culture experiment and drafted the manuscript. SS performed the experiments of tick collection, sequencing of viral genome, animal experiments, titration of virus, and cell culture experiment. NTMM helped the animal experiments. TN helped to analyze the viral sequence data. KM helped to draft the manuscript. DH performed the experiments of tick collection and animal experiments, conceived and designed the study, and drafted the manuscript. All authors read and approved the final manuscript.

\section{Competing interests}

The authors declare that they have no competing interests.

\section{Ethics approval}

The animal experiments were performed in accordance with the recommendations in the Fundamental Guidelines for the Proper Conduct of Animal Experiments and Related Activities in Academic Research Institutions under the jurisdiction of the Ministry of Education, Culture, Sports, Science, and Technology. The Animal Care and Use Committee of the Nagasaki University approved all of the experimental protocols (approval number: 1408051166, 1602031280).

Received: 9 June 2016 Accepted: 17 August 2016

Published online: 11 October 2016

\section{References}

1. Butenko AM, Gromashevsky VL, L'Vov DK, Popov VF. First isolations of Barur virus (Rhabdoviridae) from ticks (Acari: Ixodidae) in Africa. J Med Entomol. 1981;18(3):232-4.

2. Lani R, Moghaddam E, Haghani A, Chang LY, AbuBakar S, Zandi K. Tick-borne viruses: a review from the perspective of therapeutic approaches. Ticks Tick Borne Dis. 2014;5(5):457-65.

3. Davies $C R$, Jones LD, Nuttall PA. Experimental studies on the transmission cycle of Thogoto virus, a candidate orthomyxovirus, in Rhipicephalus appendiculatus. Am J Trop Med Hyg. 1986;35(6):1256-62.

4. Takahashi T, Maeda K, Suzuki T, Ishido A, Shigeoka T, Tominaga T, Kamei T, Honda M, Ninomiya D, Sakai T, et al. The first identification and retrospective study of severe fever with thrombocytopenia syndrome in Japan. J Infect Dis. 2014;209(6):816-27.

5. Takashima I, Morita K, Chiba M, Hayasaka D, Sato T, Takezawa C, Igarashi A, Kariwa H, Yoshimatsu K, Arikawa J, et al. A case of tick-borne encephalitis in Japan and isolation of the virus. J Clin Microbiol. 1997;35(8):1943-7.

6. Takeda T, Ito T, Chiba M, Takahashi K, Niioka T, Takashima I. Isolation of tick-borne encephalitis virus from Ixodes ovatus (Acari: Ixodidae) in Japan. J Med Entomol. 1998:35(3):227-31.

7. Zhang YZ, Zhou DJ, Qin XC, Tian JH, Xiong Y, Wang JB, Chen XP, Gao DY, He YW, Jin D, et al. The ecology, genetic diversity, and phylogeny of Huaiyangshan virus in China. J Virol. 2012;86(5):2864-8.

8. Suh JH, Kim HC, Yun SM, Lim JW, Kim JH, Chong ST, Kim DH, Kim HT, Kim $\mathrm{H}$, Klein TA et al. Detection of SFTS virus in Ixodes nipponensis and Amblyomma testudinarium (Ixodida: Ixodidae) collected from reptiles in the Republic of Korea. J Med Entomol. 2016.

9. Oh SS, Chae JB, Kang JG, Kim HC, Chong ST, Shin JH, Hur MS, Suh JH, Oh $M D$, Jeong SM et al. Detection of severe fever with thrombocytopenia syndrome virus from wild animals and Ixodidae ticks in the Republic of Korea. Vector Borne Zoonotic Dis. 2016;16(6):408-14.

10. Yun SM, Song BG, Choi W, Roh JY, Lee YJ, Park WI, Han MG, Ju YR, Lee WJ. First isolation of severe fever with thrombocytopenia syndrome virus from Haemaphysalis longicornis ticks collected in severe fever with thrombocytopenia syndrome outbreak areas in the Republic of Korea. Vector Borne Zoonotic Dis. 2016;16(1):66-70.

11. Park SW, Song BG, Shin EH, Yun SM, Han MG, Park MY, Park C, Ryou J. Prevalence of severe fever with thrombocytopenia syndrome virus in 
Haemaphysalis longicornis ticks in South Korea. Ticks Tick Borne Dis. 2014;5(6):975-7.

12. Li Z, Bao C, Hu J, Liu W, Wang X, Zhang L, Ji Z, Feng Z, Li L, Shen A, et al. Ecology of the tick-borne phlebovirus causing severe fever with thrombocytopenia syndrome in an endemic area of China. PLoS Negl Trop Dis. 2016;10(4):e0004574.

13. Luo LM, Zhao L, Wen HL, Zhang ZT, Liu JW, Fang LZ, Xue ZF, Ma DQ, Zhang XS, Ding SJ, et al. Haemaphysalis longicornis ticks as reservoir and vector of severe fever with thrombocytopenia syndrome virus in China. Emerg Infect Dis. 2015;21(10):1770-6.

14. Ham H, Jo S, Jang J, Choi S. No detection of severe fever with thrombocytopenia syndrome virus from ixodid ticks collected in Seoul. Korean J Parasitol. 2014;52(2):221-4.

15. Hayasaka D, Shimada S, Aoki K, Takamatsu Y, Uchida L, Horio M, Fuxun Y, Morita K. Epidemiological survey of severe fever with thrombocytopenia syndrome virus in ticks in Nagasaki, Japan. Trop Med Health. 2015;43(3):159-64.

16. Shimada S, Aoki K, Nabeshima T, Fuxun Y, Kurosaki Y, Shiogama K, Onouchi T, Sakaguchi M, Fuchigami T, Ono H, et al. Tofla virus: a newly identified nairovirus of the Crimean-Congo hemorrhagic fever group isolated from ticks in Japan. Sci Rep. 2016;6:20213.

17. Ejiri H, Lim CK, Isawa H, Kuwata R, Kobayashi D, Yamaguchi Y, Takayama-lto M, Kinoshita H, Kakiuchi S, Horiya M, et al. Genetic and biological characterization of Muko virus, a new distinct member of the species Great Island virus (genus Orbivirus, family Reoviridae), isolated from ixodid ticks in Japan. Arch Virol. 2015;160(12):2965-77.

18. Drolet BS, van Rijn P, Howerth EW, Beer M, Mertens PP. A review of knowledge gaps and tools for orbivirus research. Vector Borne Zoonotic Dis. 2015;15(6):339-47.

19. Subramanian AR, Kaufmann M, Morgenstern B. DIALIGN-TX: greedy and progressive approaches for segment-based multiple sequence alignment. Algorithms Mol Biol. 2008;3:6.

20. Subramanian AR, Weyer-Menkhoff J, Kaufmann M, Morgenstern B. DIALIGN-T: an improved algorithm for segment-based multiple sequence alignment. BMC Bioinformatics. 2005;6:66.

21. Capella-Gutierrez S, Silla-Martinez JM, Gabaldon T. trimAl: a tool for automated alignment trimming in large-scale phylogenetic analyses. Bioinformatics. 2009;25(15):1972-3.

22. Darriba D, Taboada GL, Doallo R, Posada D. ProtTest 3: fast selection of best-fit models of protein evolution. Bioinformatics. 2011;27(8):1164-5.

23. Guindon S, Dufayard JF, Lefort V, Anisimova M, Hordijk W, Gascuel O. New algorithms and methods to estimate maximum-likelihood phylogenies: assessing the performance of PhyML 3.0. Syst Biol. 2010;59(3):307-21.

24. Koressaar T, Remm M. Enhancements and modifications of primer design program Primer3. Bioinformatics. 2007;23(10):1289-91.

25. Untergasser A, Cutcutache I, Koressaar T, Ye J, Faircloth BC, Remm M, Rozen SG. Primer3-new capabilities and interfaces. Nucleic Acids Res. 2012:40(15):e115.

26. Bereczky S, Lindegren G, Karlberg H, Akerstrom S, Klingstrom J, Mirazimi A. Crimean-Congo hemorrhagic fever virus infection is lethal for adult type I interferon receptor-knockout mice. J Gen Virol. 2010;91(Pt 6):1473-7.

27. Bishop DHL. Bunyaviridae. Intervirology. 1980;14:125-43.

28. Dowall SD, Findlay-Wilson S, Rayner E, Pearson G, Pickersgill J, Rule A, Merredew N, Smith H, Chamberlain J, Hewson R. Hazara virus infection is lethal for adult type I interferon receptor-knockout mice and may act as a surrogate for infection with the human-pathogenic Crimean-Congo hemorrhagic fever virus. J Gen Virol. 2012;93(Pt 3):560-4.

29. Rushton J, Lyons N. Economic impact of Bluetongue: a review of the effects on production. Vet Ital. 2015;51(4):401-6.

30. Ruder MG, Stallknecht DE, Allison AB, Mead DG, Carter DL, Howerth EW. Host and potential vector susceptibility to an emerging orbivirus in the United States: epizootic hemorrhagic disease virus serotype 6. Vet Pathol. 2015

\section{Submit your next manuscript to BioMed Central and we will help you at every step:}

- We accept pre-submission inquiries

- Our selector tool helps you to find the most relevant journal

- We provide round the clock customer support

- Convenient online submission

- Thorough peer review

- Inclusion in PubMed and all major indexing services

- Maximum visibility for your research

Submit your manuscript at www.biomedcentral.com/submit
Biomed Central 